\title{
Childhood history of abuse and child abuse potential: The role of parent's gender and timing of childhood abuse
}

\author{
A. Romero-Martínez ${ }^{\mathrm{b}}$, B. Figueiredo ${ }^{\mathrm{a}}$, L. Moya-Albiol ${ }^{\mathrm{b}, *}$ \\ a School of Psychology, University of Minho, Portugal \\ ${ }^{\mathrm{b}}$ Department of Psychobiology, University of Valencia, Spain
}

\section{A R T I C L E I N F O}

\section{Article history:}

Received 9 July 2013

Received in revised form

20 September 2013

Accepted 23 September 2013

Available online $\mathrm{xxx}$

\section{Keywords:}

Child abuse

Cycle of violence

Parenting

Potential abuse

Timing

\begin{abstract}
A B S T R A C T
It has been suggested that being physically abused leads to someone becoming a perpetrator of abuse which could be associated to parents' gender, timing of the physical abuse and specific socio-demographic variables. This study aims to investigate the role the parents' gender, timing of childhood abuse and socio-demographic variables on the relationship between parents' history of childhood physical abuse and current risk for children. The sample consisted of 920 parents ( 414 fathers, 506 mothers) from the Portuguese National Representative Study of Psychosocial Context of Child Abuse and Neglect who completed the Childhood History Questionnaire and the Child Abuse Potential Inventory. The results showed that fathers had lower current potential risk of becoming physical abuse perpetrators with their children than mothers although they did not differed in their physical victimization history. Moreover, the risk was higher in parents (both genders) with continuous history of victimization than in parents without victimization. Prediction models showed that for fathers and mothers separately similar socio-demographic variables (family income, number of children at home, employment status and marital status) predicted the potential risk of becoming physical abuses perpetrators. Nevertheless, the timing of victimization was different for fathers (before 13 years old) and mothers (after 13 years old). Then our study targets specific variables (timing of physical abuse, parents' gender and specific socio-demographic variables), which may enable professionals to select groups of parents at greater need of participating in abuse prevention programs.
\end{abstract}

(c) 2013 Elsevier Ltd. All rights reserved.

\section{Introduction}

Being physically abused leads to someone becoming a perpetrator of abuse (Caykoylu, Ibiloglu, Taner, Potas, \& Taner, 2011; Paúl, Milner, \& Múgica, 1995; Newcomb \& Locke, 2001; Rikhye et al., 2008; Simons, Whitbeck, Conger, \& ChyiIn,1991; Zaidi, Knutson, \& Mehm, 1989). That would be partially explained by structural and functional brain abnormalities in maltreated children (Mesa-Gresa \& Moya-Albiol, 2011). Moreover, the early social learning models might explain the intergenerational transmission of abusive parent behavior (Muller, Hunter, \& Stollak, 1995). Such models might explain why both childhood receipt of physical abuse and observation of spousal abuse impact on adult likelihood of child maltreatment (Schluter, Tautolo, \& Paterson, 2011). Further models such as attachment and trauma mediation models could explain the intergenerational transmission of parents' abusive behaviors with their offspring (Amos, Furber, \& Segal, 2011; Joubert, Webster, \& Hackett, 2012; Morton \& Browne, 1998; Rodriguez \& Tucker, 2011). Parents who were abused can also use more frequently the punitive discipline techniques that they received (Rodriguez \& Sutherland, 1999). This process was defined as the 'cycle of violence'. Perpetuating factors are those that affect the family in a continuing or ongoing way. The relationship

\footnotetext{
* Corresponding author at: Department of Psychobiology, University of Valencia, Avenida Blasco Ibañez, 21, 46010 Valencia, Spain.
} 
between the effects of being abused during childhood and the medium and long term effects is moderated by different variables such as the kind of abuse, its intensity and duration and the child's gender (Mesa-Gresa \& Moya-Albiol, 2011).

For women, physical abuse in childhood significantly influenced perceptions of their relationship with children. However, physical abuse was not significantly associated with later parenting in fathers (Sandberg, Feldhousenb, \& Busbya, 2012). Typically, more mothers use physical punishment than fathers (Ferrari, 2002; Uslu, Kapci, Yildirim, \& Oney, 2010), although fathers were highly over-represented as perpetrators of physical child abuse, particularly in its most severe forms (Guterman \& Lee, 2005). However, some studies did not show differences between fathers and mothers as perpetrators of abuse on their offspring (Browne \& Hamilton, 1998; Nobes, Smith, Upton, \& Heverin, 1999). Physical abuse was confined to family members and its prevalence rates were similar in different cultures (Stoltenborgh, Bakermans-Kranenburg, van Ijzendoorn, \& Alink, 2013). Most physical abuses began prior to the age of 13, with half continuing after that age (Marysko et al., 2010; Sushil et al., 2004). Children (both genders) who experienced physical abuse prior to puberty presented higher rates of abusive behaviors than those with physical abuse after puberty (de Paúl \& Domenech, 2000; Milner, Robertson, \& Rogers, 1990), and a recent study found that childhood-limited maltreatment does not significantly increase the odds of maltreatment perpetration. However, maltreatment victimization, especially during adolescence or beginning in childhood and persisting into adolescence, is a likely cause of subsequent perpetration. Thus, developmental theories sustain that what occurs early in the life has a significant importance for later development. Nevertheless, for life-course theories, recent as well as distant events are important for the course of life (Thornberry \& Henry, 2013).

Physically abusive families had significantly more often a low income and less education, younger parents, and more frequently presented a family history of physical victimization (Caliso \& Milner, 1992; de Paúl \& Domenech, 2000; Wolfe, Edwards, Manion, \& Koverola, 1988; Whipple \& Webster-Stratton, 1991), had social isolation, marital problems and more children than they could handle as well as a poor supporting environment (Dietrich, Berkowitz, Kadushin, \& McGloin, 1990; Hıdıroğlu, Topuzoğlu, Ay, \& Karavuş, 2006; Moracco, Runyan, Bowling, \& Earp, 2007; Ünal, 2005). The absence of that socioeconomic resources and abilities act as a catalytic factor for becoming perpetrators of physical abuse, in parents with a previous history of physical victimization (Whipple \& Webster-Stratton, 1991).

With all this in mind, using data from a community survey with Portuguese parents, the aim of the current investigation was twofold. First, we investigated whether the parents' gender and the timing of the parents' history of abuse affects the current risk of becoming physical abuse perpetrators with their children. As mothers classically tend to be more physically aggressive with their offspring than fathers (Appel \& Holden, 1998; U.S. Department of Health \& Human Services, 2006), we would expect that mothers presented a higher risk of maltreating their children than fathers. Moreover, as the history of childhood abuse (earlier, during adolescence or continuous) increases the rate of becoming a perpetrator of abuse in adulthood (de Paúl \& Domenech, 2000; Milner et al., 1990; Thornberry \& Henry, 2013), we would expect that parents (both genders) with some history of abuse during their early lives (in adolescence or continuous) presented higher predisposition to child abuse than parents without history of childhood abuse. Finally, the role of parents' childhood experience of physical maltreatment during childhood and adolescence (before, after 13 and before + after 13) and socio-demographic variables on the predispositions to child abuse in parents, separately for fathers and mothers, will be examined. Considering the importance of the continuous history of abuse to become an abuse perpetrator (de Paúl \& Domenech, 2000; Milner, Robertson, \& Rogers, 1990; Thornberry \& Henry, 2013), we would expect that in parents (both genders), continuous history of abuse would be a better predictor of predisposition to child abuse. Moreover, due to the importance of some socio-demographic variables such as educational level, employment status, family income, parents' age and number of children, in the intergenerational continuity of child maltreatment (Appleyard, Berlin, Rosanbalm, \& Dodge, 2011; Gilbert et al., 2009; Stith et al., 2009), we would expect to find that low economic level, parent's age, professional status and/or educational level together with a high number of children increased the risk of offspring maltreatment, independently of the parents' gender. Given the importance of this complex research topic for understanding the cycle of human violence and for establishing effective prevention programs, we first need to understand the nature and strength of the relationship between a history of maltreatment victimization and the potential risk of becoming physical abuse perpetrators.

\section{Method}

\section{Participants}

The sample was composed by 920 parents that participated in the National Representative Study of Psychosocial Context of Child Abuse and Neglect in Portugal. Parents ranged from 22 to 66 in age and had on average 1.92 children (SD $=0.91$, range $=1-9)$. The overall rate of compliance from parents (i.e., in returning the questionnaires) was $69 \%(N=1021)$, and the rate of correctly completed and returned questionnaires was $63 \%$ [ $68 \%(506)$ for mothers and $58 \%(414)$ for fathers].

\section{Procedure}

Participants were a subset of parents in the National Representative Study of Psychosocial Context of Child Abuse and Neglect in Portugal (PCCANP). Participants were mothers and fathers of children randomly selected in five public elementary schools of Northern Portugal. All parents whose children attended the selected schools were contacted in the year 2000. Regional education authorities (DREN, Direção Regional da Educação do Norte) provided ethical approval for the current 
Table 1

Mean \pm SEM and distribution of socio-demographic variables for fathers and mothers.

\begin{tabular}{|c|c|c|}
\hline & \multicolumn{2}{|l|}{ Parents $(n=920)$} \\
\hline & Mothers $(n=506)$ & Fathers $(n=414)$ \\
\hline Age & $35.81 \pm 5.59$ & $38.70 \pm 6.60$ \\
\hline Number of children & $1.94 \pm 0.92$ & $1.90 \pm 0.27$ \\
\hline Number of children at home & $1.08 \pm 0.27$ & $1.11 \pm 0.31$ \\
\hline \multicolumn{3}{|l|}{ Marital status ${ }^{* * *}$} \\
\hline Married/cohabiting & $84 \%$ & $93 \%$ \\
\hline Divorced/widow/single & $16 \%$ & $7 \%$ \\
\hline \multicolumn{3}{|l|}{ Educational level $^{* *}$} \\
\hline$\leq 12$ years & $74 \%$ & $71 \%$ \\
\hline College degrees & $26 \%$ & $29 \%$ \\
\hline \multicolumn{3}{|l|}{ Employment status } \\
\hline Employed & $76 \%$ & $92 \%$ \\
\hline Unemployed & $24 \%$ & $8 \%$ \\
\hline Retired/other & $0 \%$ & $0 \%$ \\
\hline \multicolumn{3}{|l|}{ Family income } \\
\hline$\leq 3.5$ national minimum wage & $60 \%$ & $53 \%$ \\
\hline$\geq 3.6$ national minimum wage & $40 \%$ & $47 \%$ \\
\hline \multicolumn{3}{|l|}{ Parents' household composition } \\
\hline With spouse and with child(ren) & $88 \%$ & $96 \%$ \\
\hline Alone with children & $12 \%$ & $4 \%$ \\
\hline
\end{tabular}

research. All parents were informed about the research aims and ethic procedures in meeting sessions with research team members and teachers. For more details see Sushil et al. (2004) and Lamela and Figueiredo (2013).

\section{Measures}

Socio-demographic data. Participants were interviewed to assess socio-demographic variables such as gender (mother/father), age, number of children in the family, number of children in the family who lived at home, marital status (married/cohabiting, divorced/widow/single), educational level (<12 years, college degrees), parent employment status (employed, unemployed, retired/other), family income ( $\leq 3.5$ national minimum wage, $\geq 3.6$ national minimum wage) and parents' household composition (with spouse and with child(ren), alone with children) (see Table 1).

Childhood History Questionnaire (CHQ). The Portuguese version (Sushil et al., 2004) of the Childhood History Questionnaire (Milner et al., 1990), which is a retrospective, self-report, assessed the parents' childhood experience of physical maltreatment during childhood and adolescence. The main CHQ question is: "As a child, did you receive any of the following from one of your parents or another adult before you were 13?" For each item the respondent is asked to identify the perpetrator when relevant. The CHQ presented nine physically maltreatment events (i.e., whipping, slapping/kicking, bruises/welts, bone fractures) and participants were asked for the presence or absence $(0=$ no, $1=$ yes $)$ of occurrence of each one of them, prior to and after age 13. To reduce the number of tests, increase power for effect size, and aid interpretation within a conceptual framework, a general physically maltreatment event index is calculated by adding the scores of the items of four subscales, before 13 (physical without sequelae/injury and physical with sequelae/injury) and after 13 (physical without sequelae/injury and physical with sequelae/injury), ranging from 0 to 4 for the total score. The Cronbach's $\alpha$ of the Portuguese adaptation was 81 .

Child Abuse Potential Inventory (CAPI). The Portuguese version (Gomes, 2010) of the Child Abuse Potential Inventory (CAPI) was employed to assess parents' attitudes and practices regarding physical forms of discipline and abuse (Milner, 1986). The Portuguese adaptation of the CAPI abuse scale include a 77-item Child Abuse Scale (which examines distress, rigidity, unhappiness, problems with the child and the self, problems with the family and with others, and others' problems (i.e., 'Children should never disobey', 'A good child keeps his toys and clothes clean and tidy')) and 3 validity scales. These three scales include: the lie scale (18 items), the random response scale (18 items), and the inconsistency scale (20 items). Items are answered in a forced-choice format ( 0 , no or 1 , yes). Total score employed in our study on CAPI physical abuse scale ranges from 0 to 74, with higher scores reflecting a higher risk of child physical abuse. Cronbach's $\alpha$ was .88.

\section{Data analysis}

After confirming the normality of the data using the Kolmogorov-Smirnov test, $T$-tests with Levene's test and/or Chi square analyses were performed where appropriate were used to check for significant gender differences in parents' CHQ total scores and socio-demographic variables. Effect sizes for the between-group differences were calculated using Cohen's 
Table 2

Distribution of physical abuse (Childhood History Questionnaire (CHQ) for fathers and mothers).

\begin{tabular}{lllll}
\hline & Without physical abuse, $\%(N)$ & Before 13 only, \% $(N)$ & After 13 only, \% $(N)$ & Before and after13, \% $(\mathrm{N})$ \\
\hline Fathers $(n=414)$ & $24.3 \%$ & $27.6 \%$ & $3.3 \%$ & $44.9 \%$ \\
Mothers $(n=506)$ & $26.9 \%$ & $29.3 \%$ & $2.7 \%$ & $41.1 \%$ \\
\hline
\end{tabular}

$d$ (Cohen, 1988). One-way ANOVA was conducted with 'gender' and 'timing of the childhood abuse (before 13, after 13 or before + after 13)' as between-subject factors. Afterwards, one-way ANCOVA was conducted with 'gender' and 'timing of the childhood abuse (before 13, after 13 or before + after 13)' as between-subject factors and appropriate covariates (socio-demographic variables).

Hierarchical linear regressions were performed to predict separately for fathers and mothers the predisposition to child abuse in parents using as potential predictors the parents' childhood experience of physical maltreatment during childhood and adolescence (before, after 13 and before + after 13) and socio-demographic variables.

Data analyses were performed using SPSS 19.0 (SPSS IBM). All reported $p$-values are two-tailed, and $p \leq .05$ was considered significant. Average values are expressed as mean \pm SEM.

\section{Results}

\section{General differences between fathers and mothers}

Fathers did not differ significantly from mothers in the number of children and the number of children who live at home. Nonetheless, there were significant differences in terms of age $\left(t_{938}=-.7 .24, p=.000, d=.47\right)$, marital status $\left(\chi^{2}(4)=20.38\right.$, $p=.000)$, educational level $\left(\chi^{2}(7)=19.44, p=.007\right)$, employment status $\left(\chi^{2}(1)=4.91, p=.000\right)$, family income $\left(\chi^{2}(4)=13.47\right.$, $p=.009)$ and parents' household composition $\left(\chi^{2}(2)=45.04, p=.000\right)$. Fathers were older, more were married, had higher educational level employment status and income, and less lived alone with children than women (see Table 1). For this reason, they were covariated in the ulterior analysis.

No significant differences were found between fathers and mothers in the total scores of CHQ physical abuse before 13 $(0.80 \pm 0.50$ and $0.82 \pm 0.03$, respectively), physical abuse after $13(0.51 \pm 0.03$ and $0.54 \pm 0.03$, respectively) or total physical abuse (before + after 13) $(1.36 \pm 0.05$ and $1.31 \pm 0.05$, respectively). Moreover, no significant effect of gender in the percentage of distribution of CHQ presence or not of physical abuse was detected (see Table 2).

A significant 'gender' $\left[F(1,919)=15.39, p=.000, \eta_{p}^{2}=.02\right]$ and 'timing of history of childhood physical abuse' $[F(3$, $916)=4.73, p=.003, \eta_{p}^{2}=.02$ ] effect was found in the CAPI score and in the potential risk of becoming a perpetrator of physical abuse. Fathers presented lower risk than mothers in their predisposition to child abuse $(20.38 \pm 0.56$ and $24.88 \pm 0.54$, respectively) and parents with a continuous history of physical abuse showed higher CAPI score than parents without history of physical abuse $(23.85 \pm 0.65$ and $20.84 \pm 0.69$, respectively) $(p<.05)$. However, a significant effect of the 'interaction gender $\times$ timing of history of childhood physical abuse' was not observed. After covariate the socio-demographic variables, similar results were obtained, with 'gender' $\left[F(1,863)=18.77, p=.000, \eta_{p}^{2}=.02\right]$ and timing of history of childhood physical abuse $\left[F(3,863)=7.84, p=.000, \eta_{p}^{2}=.03\right]$ presenting a significant effect on CAPI score. Finally, the interaction 'gender $\times$ timing of history of childhood physical abuse' did not show a significant effect.

Hierarchical regression models with predictors of predisposition to child abuse in parents (timing of parents' childhood experience of physical maltreatment and socio-demographic variables) separately for fathers and mothers, are summarized in Table 3.

\section{Discussion}

Fathers had lower current potential risk of becoming perpetrators of physical abuse with their children than mothers. Moreover, parents (both genders) with a continuous (before + after 13 years old) history of childhood physical abuse presented a higher potential risk of becoming perpetrators of physical abuse with their children than parents without any history of physical abuse. Fathers and mothers did not differ in terms of parents' history of childhood physical victimization (before, after 13 and before + after 13 years old). Regarding the predictors of the potential risk of becoming perpetrators of physical abuse with their children, the best one for fathers was the history of childhood victimization before 13 years old while for mothers it was the history of childhood victimization after 13 years old. For both, fathers and mothers, similar sociodemographic variables (family income, number of children at home, employment status and marital status) predicted the potential risk of becoming perpetrators of physical abuse with their children. Nevertheless, only in mothers the educational level was a predictor of the potential risk of becoming a perpetrator.

We hypothesized that mothers would present a higher potential risk of becoming perpetrators of physical abuse with their children than fathers and our results support that hypothesis. Moreover, our data also revealed that parents (fathers and mothers) persistently or continuously maltreated had a higher likelihood of becoming perpetrators of physical abuse with their own children. These results could be explained because mothers tend to bear a larger share of parenting responsibilities in two-parent families and spend significantly more time caring for children (Appel \& Holden, 1998; U.S. Department of 
Table 3

Linear regression models with parents' demographics and parents' CAPI for fathers and mothers.

\begin{tabular}{|c|c|c|c|c|c|}
\hline \multirow[t]{2}{*}{ Predictor } & \multicolumn{5}{|c|}{ Fathers $(n=414)$} \\
\hline & Multiple $R^{2}$ & $R$ change & $F($ model $)$ & $B$ coefficient & Sig. \\
\hline \multicolumn{6}{|l|}{ Model 5} \\
\hline Family income & .182 & $.010^{* *}$ & $F(5,265)-1722^{* * * *}$ & -.293 & .039 \\
\hline Number of children at home & & & $F(5,365)=17.23$ & .152 & .000 \\
\hline Employment status & & & & .140 & .006 \\
\hline CHQ before 13 & & & & .120 & .005 \\
\hline Marital status & & & & .103 & .032 \\
\hline \multirow[t]{2}{*}{ Predictor } & \multicolumn{5}{|c|}{ Mothers $(n=506)$} \\
\hline & Multiple $R^{2}$ & $R$ change & $F($ model $)$ & $B$ coefficient & Sig. \\
\hline \multicolumn{6}{|l|}{ Model 6} \\
\hline Family income & .235 & $.012^{* *}$ & & -.179 & .000 \\
\hline CHQ after 13 & & & $F(7,439)=23.49$ & .187 & .003 \\
\hline Number of children at home & & & & .213 & .000 \\
\hline Number of children & & & & .141 & .001 \\
\hline Educational level & & & & -.160 & .001 \\
\hline Employment status & & & & .120 & .011 \\
\hline
\end{tabular}

${ }^{* * *} p<.01$.

*** $p<.001$.

Health \& Human Services, 2006). Social learning theories sustain that maltreated parents apply the same procedures they learned from their own parents or in their context (Coulton, Korbin, Su, \& Chow, 1995; Kotch et al., 1995; Muller et al., 1995; Schellenbach, Whitman, \& Borkowski, 1992; Schluter et al., 2011; Uslu et al., 2010). Attending to the attachment theory, parents who maltreat their own children present insecure and disorganized attachments as a result of their own experience with their parent's sensitivity and responsiveness (Amos et al., 2011). Finally, ecological theories sustain that intergenerational transmission of maltreatment is a result of mediation processes such as learning of a cultural discipline, poor emotion regulation, hostile traits, antisocial traits, and dissociative symptoms (Cicchetti \& Valentino, 2006). In our study, mothers presented a higher potential risk of becoming perpetrators of physical abuse than fathers although they did not differ in their childhood victimization history. Moreover, the differences between socio-demographic variables which could explain the potential risk of becoming abuse perpetrators (Dietrich et al., 1990; Hıdıroğlu et al., 2006; Moracco et al., 2007; Ünal, 2005) were statistically controlled and the same results were obtained. For that, it was important to analyze mediator variables such as the timing of maltreatment and the relationship between parents who were maltreated with the possibility to eventually maltreat their own.

Usually only the kind of abuse, its intensity and duration and the child's gender were considered as moderators in the effects of maltreatment in children (Mesa-Gresa \& Moya-Albiol, 2011). However, our data reveal the importance of the timing of physical maltreatment for fathers and mothers on the cycle of violence. In the case of fathers it was worst being physically maltreated before the age of 13 and in mothers after that age. The use of physical punishment during childhood and adolescence could increase the risk of suicidal ideation, depression, drug abuse, wife assaults, and child abuse in later life. However, the link is better established in childhood than in adolescence (Smith, Ireland, \& Thornberry, 2005; Straus \& Kantor, 1994). Gender differences of maltreatment's timing for the cycle of violence could be partially explained by differential organic and psychological development which are critical for the identity and a life narrative (Habermas \& Bluck, 2000), the severity and frequency of physical assaults (Straus, Gelles, \& Steinmetz, 1980) and/or the parallel history of witnessing one's own parents', sisters' and/or brothers' (Milner et al., 1990). The early physical maltreatment could be a better predictor of the current to potential risk of becoming a perpetrator of physical child maltreatment in fathers, maybe because the assault was more severe on young males (Straus et al., 1980) and/or they had a worst brain sensitivity to aversive consequences (De Bellis, 2005; De Bellis \& Kuchibhatla, 2006). Moreover, in the statistical model the socio-demographic variables were also important. Thus, the role of environmental stressors such as a low family income, employment and marital status and/or the number of children at home, together with the previous history of physical victimization could partially explain the potential risk of becoming physical assault perpetrators (Uslu et al., 2010). Hence, our results supported previous findings which proposed that physically abusive families had more often significantly low income and less education, parents were younger, and more frequently presented a family history of physical victimization (Caliso \& Milner, 1992 ; de Paúl \& Domenech, 2000; Whipple \& Webster-Stratton, 1991; Wolfe et al., 1988). Regarding mothers, the model pointed out the importance of the maltreatment after 13 years old, together with the stress derived of similar socio-demographic variables that affected fathers. It has been hypothesized that a cognitive process such as autobiographical memory of adolescent women is more elaborated, coherent and reflective than that of adolescent men (Fivusha, Bohanekb, Zamana, \& Grapinc, 2012). Hence, the maltreatment during adolescence could be more intense, in general, for women. Nonetheless, previous studies suggested that mothers permanently victimized (childhood and adulthood) had poorer outcomes than mothers 
victimized only during early childhood or adolescence (Dubowitz et al., 2001). Thus, further research is needed to analyze the importance of timing on the cycle of violence.

A limitation of our study is the cross-sectional and non-experimental design with which causality could not be addressed. Additionally, some caution should be taken in the interpretation of our findings because parents' history of physical victimization was assessed by a retrospective self-report questionnaire which may involve substantial rate of false negatives and considerable measurement errors. For this reason, future work might replicate these findings contemplating whether fathers and mothers may be from the same family, the co-occurrence of spouse and physical child abuse and the witnessing of brother or sister physical abuse. Moreover, the analysis of biological markers such as the testosterone/cortisol ratio and the neuropsychological deficits or the prenatal testosterone exposition (Romero-Martínez, Lila, Catalá-Miñana, Williams, \& Moya-Albiol, 2013; Romero-Martínez, González-Bono, Lila, Moya-Albiol, 2013; Romero-Martínez, Lila, Sariñana-González, González-Bono, Moya-Albiol, 2013; Romero-Martínez \& Moya-Albiol, 2013) as moderators on the relationship between the history of physical victimization and the potential risk of becoming a physical abuse perpetrator could benefit the findings offering a wider explanation of that complex phenomenon.

In conclusion, the timing of history of physical abuse in parents, the presence of continuous history of physical abuse, the parents gender and low socio-economic resources and abilities, are relevant factors to disrupt parenting practices and contribute to a heightened likelihood of occurrence of physical abusive strategies in parents that reported to be victims of more frequent physical maltreatment behaviors from a primary caregiver in childhood. These findings offer strong support for the cycle of maltreatment hypothesis and highlight the necessity for future research to identify the mediating processes that link generations in this maladaptive way. Our study target specific variables (timing of physical abuse, parents' gender and specific socio-demographic variables) which may enable professionals to select groups of parents who are in a greater need of participating in abuse prevention programs. It is important to develop intervention strategies and models to address and study the risk profiles of abusive parents, the parents needs, the education in secure attachment as well as other strategies to work with parents in order to increase the protective and resilient variables and minimize the potential risk elements of physical child abuse.

\section{Acknowledgments}

This work was supported by the Portuguese Foundation of Science and Technology through a research grant to the second author (POCTI/PSI/14276/1998), the Spanish Ministry of Health, Social Services and Equality, National Drug Plan (2012/001) and by the Regional Government of Valencia, Programa VALi+d para investigadores en formacion (ACIF/2011/075), research groups and networks of excellence (PROMETEO/2011/048; ISIC/2013/001).

\section{References}

Amos, J., Furber, G., \& Segal, L. (2011). Understanding maltreating mothers: A synthesis of relational trauma, attachment disorganization, structural dissociation of the personality, and experiential avoidance. Journal of Trauma Dissociation, 12(5), 495-509. http://dx.doi.org/10.1080/15299732.2010.514846 Appel, A. E., \& Holden, G. W. (1998). The co-occurrence of spouse and physical child abuse: A review and appraisal. Journal of Family Psychology, 12(4), 578-599.

Appleyard, K., Berlin, L., Rosanbalm, K., \& Dodge, K. (2011). Preventing early child maltreatment: Implications from a longitudinal study of maternal abuse history, substance use problems, and offspring victimization. Prevention Science, 12, 139-149. http://dx.doi.org/10.1111/j.1467-8624.2010.01547.x

Browne, K. D., \& Hamilton, C. E. (1998). Physical violence between young adults and their parents: Associations with a history of child maltreatment. Journal of Family Violence, 13, 59-79.

Caliso, J. A., \& Milner, J. S. (1992). Childhood history of abuse and child abuse screening. Child Abuse \& Neglect, 16, 647-659. http://dx.doi.org/10.1016/0145-2134(92)90103-X

Caykoylu, A., Ibiloglu, A. O., Taner, Y., Potas, N., \& Taner, E. (2011). The correlation of childhood physical abuse history and later abuse in a group of Turkish population. Journal of Interpersonal Violence., 26(17), 3455-3475. http://dx.doi.org/10.1177/0886260511403748

Cicchetti, D., \& Valentino, K. (2006). An ecological transactional perspective on child maltreatment: Failure of the average expectable environment and its influence upon child development. In D. Cicchetti, \& D. J. Cohen (Eds.), Developmental psychopathology: Risk, disorder, and adaptation (Vol. 3) (pp. 129-201). New York: Wiley.

Cohen, J. (1988). Statistical power analysis for the behavioral sciences (2nd ed.). New Jersey: Lawrence Erlbaum.

Coulton, C. J., Korbin, J. E., Su, M., \& Chow, J. (1995). Community level factors and child maltreatment rates. Child Development, 66, $1262-1276$. http://dx.doi.org/10.1111/j.1467-8624.1995.tb00934.x

De Bellis, M. D. (2005). The psychobiology of neglect. Child Maltreatment, 10, 150-172. http://dx.doi.org/10.1177/1077559505275116

De Bellis, M. D., \& Kuchibhatla, M. (2006). Cerebellar volumes in pediatric maltreatment-related posttraumatic stress disorder. Biological Psychiatry, 60, 697-703. http://dx.doi.org/10.1016/j.biopsych.2006.04.035

de Paúl, J., \& Domenech, L. (2000). Childhood history of abuse and child abuse potential in adolescent mothers: A longitudinal study. Child Abuse E Neglect, 24(5), 701-713. http://dx.doi.org/10.1016/S0145-2134(00)00124-1

de Paúl, J., Milner, J. S., \& Múgica, P. (1995). Childhood maltreatment, childhood social support, and child abuse potential in a Basque sample. Child Abuse \& Neglect, 19(8), 907-920. http://dx.doi.org/10.1016/0145-2134(95)00053-B

Dietrich, D., Berkowitz, L., Kadushin, A., \& McGloin, J. (1990). Some factors influencing abusers' justification of their child abuse. Child Abuse E Neglect, 14, 337-345. http://dx.doi.org/10.1016/0145-2134(90)90005-E

Dubowitz, H., Black, M. M., Kerr, M. A., Hussey, J. M., Morrel, T. M., Everson, M. D., \& Starr, R. H., Jr. (2001). Type and timing of mothers' victimization: Effects on mothers and children. Pediatrics, 107(4), 728-735

Ferrari, A. M. (2002). The impact of culture upon child rearing practices and definitions of maltreatment. Child Abuse E' Neglect, 26, 793-813.

Fivusha, R., Bohanekb, J. G., Zamana, W., \& Grapinc, S. (2012). Gender differences in adolescents' autobiographical narratives. Journal of Cognitive Development, 13(3), 295-319. http://dx.doi.org/10.1080/15248372.2011.590787

Figueiredo, B., Bifulco, A., Paiva, C., Maia, A., Fernandes, E., \& Matos, R. (2004). History of childhood abuse in Portuguese parents. Child Abuse E Neglect, 28(6), 669-682. http://dx.doi.org/10.1016/j.chiabu.2003.11.021 
Gilbert, R., Widom, C., Browne, K., Fergusson, D., Webb, E., \& Janson, S. (2009). Burden and consequences of child maltreatment in high-income countries. Lancet, 373, 68-81. http://dx.doi.org/10.1016/S0140-6736(08)61706-7

Gomes, J. (2010). Validation of the Portuguese version of the Child Abuse Potential Inventory. Braga: University of Minho.

Guterman, N. B., \& Lee, Y. (2005). The role of fathers in risk for physical child abuse and neglect: Possible pathways and unanswered questions. Child Maltreatment, 10(2), 136-149. http://dx.doi.org/10.1177/1077559505274623

Habermas, T., \& Bluck, S. (2000). Getting a life: The emergence of the life story in adolescence. Psychological Bulletin, 126(5), 748-769. http://dx.doi.org/10.1037/0033-2909.126.5.748

Hıdıroğlu, S., Topuzoğlu, A., Ay, P., \& Karavuș, M. (2006). Risk factors for physical abuse towards children and women. New Symposium Journal, 44, 196-202.

Joubert, D., Webster, L., \& Hackett, R. K. (2012). Unresolved attachment status and trauma-related symptomatology in maltreated adolescents: An examination of cognitive mediators. Child Psychiatry \& Human Development, 43(3), 471-483. http://dx.doi.org/10.1007/s10578-011-0276-8

Kotch, J. B., Browne, D. C., Ringwalt, C. L., Stewart, P. W., Ruina, E., Holt, K., Lowman, B., \& Jung, J. W. (1995). Risk of child abuse or neglect in a cohort of low-income children. Child Abuse E Neglect, 19, 1115-1130. http://dx.doi.org/10.1016/0145-2134(95)00072-G

Lamela, D., \& Figueiredo, B. (2013). Parents' physical victimization in childhood and current risk of child maltreatment: The mediator role of psychosomatic symptoms. Journal of Psychosomatic Research, 75(2), 178-183. http://dx.doi.org/10.1016/j.jpsychores.2013.04.001

Marysko, M., Reck, C., Mattheis, V., Finke, P., Resch, F., \& Moehler, E. (2010). History of childhood abuse is accompanied by increased dissociation in young mothers five months postnatally. Psychopathology, 43(2), 104-109. http://dx.doi.org/10.1159/000276999

Mesa-Gresa, P., \& Moya-Albiol, L. (2011). Neurobiología del maltrato infantil: El ciclo de la violencia [Neurobiology of child abuse: The 'cycle of violence']. Revista Neurologia, 52(8), 489-503.

Milner, J. (1986). Child Abuse Potential Inventory: Manual. Webster, NC: Psytec.

Milner, J. S., Robertson, K. R., \& Rogers, D. B. (1990). Childhood history of abuse and adult child abuse potential. Journal of Family Violence, 5(1), 15-34.

Moracco, K. E., Runyan, C. W., Bowling, J. M., \& Earp, J. A. (2007). Women's experiences with violence: A national study. Women's Health Issues, 17(1), 3-12.

Morton, N., \& Browne, K. D. (1998). Theory and observation of attachment and its relation to child maltreatment: A review. Child Abuse E Neglect, 22(11), 1093-1104. http://dx.doi.org/10.1016/S0145-2134(98)00088-X

Muller, R. T., Hunter, J. E., \& Stollak, G. (1995). The intergenerational transmission of corporal punishment: A comparison of social learning and temperament models. Child Abuse \& Neglect, 19(11), 1323-1335. http://dx.doi.org/10.1016/0145-2134(95)00103-F

Newcomb, M., \& Locke, T. (2001). Intergenerational cycle of maltreatment: A popular concept obscured by methodological limitations. Child Abuse \& Neglect, 25, 1219-1240. http://dx.doi.org/10.1016/S0145-2134(01)00267-8

Nobes, G., Smith, M., Upton, P., \& Heverin, A. (1999). Physical punishment by mothers and fathers in British homes. Journal of Interpersonal Violence, 14, $887-902$.

Rikhye, K., Tyrka, A. R., Kelly, M. M., Gagne, G. G., Jr., Mello, A. F., Mello, M. F., Price, L. H., \& Carpenter, L. L. (2008). Interplay between childhood maltreatment, parental bonding, and gender effects: Impact on quality of life. Child Abuse E Neglect, 32(1), 19-34. http://dx.doi.org/10.1016/j.chiabu.2007.04.012

Rodriguez, C. M., \& Sutherland, D. (1999). Predictors of parents' physical disciplinary practices. Child Abuse E Neglect, $23(7)$, 651-657. http://dx.doi.org/10.1016/S0145-2134(99)00043-5

Rodriguez, C. M., \& Tucker, M. C. (2011). Behind the cycle of violence, beyond abuse history: A brief report on the association of parental attachment to physical child abuse potential. Violence and Victims, 26(2), 246-256.

Romero-Martínez, A., Lila, M., Catalá-Miñana, A., Williams, R. K., \& Moya-Albiol, L. (2013). The contribution of childhood parental rejection and early androgen exposure to impairments in socio-cognitive skills in intimate partner violence perpetrators with high alcohol consumption. International Journal of Environmental Research and Public Health, 10(8), 3753-3770. http://dx.doi.org/10.3390/ijerph10083753

Romero-Martínez, A., González-Bono, E., Lila, M., \& Moya-Albiol, L. (2013). Testosterone/cortisol ratio in response to acute stress: A possible marker of risk for marital violence. Social Neuroscience, 8(3), 240-247. http://dx.doi.org/10.1080/17470919.2013.772072

Romero-Martínez, A., Lila, M., Sariñana-González, P., González-Bono, E., \& Moya-Albiol, L. (2013). High testosterone levels and sensitivity to acute stress in perpetrators of domestic violence with low cognitive flexibility and impairments in their emotional decoding process: A preliminary study. Aggressive Behavior, 39(5), 355-369. http://dx.doi.org/10.1002/ab.21490

Romero-Martínez, A., \& Moya-Albiol, L. (2013). Neuropsychology of perpetrators of domestic violence: The role of traumatic brain injury and alcohol abuse and/or dependence. Revista Neurologia (in press).

Sandberg, J. G., Feldhousenb, E. B., \& Busbya, D. M. (2012). The impact of childhood abuse on women's and men's perceived parenting: Implications for practitioners. American Journal of Family Therapy, 40(1), 74-91. http://dx.doi.org/10.1080/01926187.2011.566827

Schellenbach, C. J., Whitman, T. L., \& Borkowski, J. G. (1992). Toward an integrative model of adolescent parenting. Human Development, 35, 81-99. http://dx.doi.org/10.1159/000277136

Schluter, P. J., Tautolo, El.-S., \& Paterson, J. (2011). Experience of physical abuse in childhood and perpetration of physical punishment and violence in adulthood amongst fathers: Findings from the Pacific Islands Families Study. Pacific Health Dialogue, 17(2), 148-162.

Simons, R. L., Whitbeck, L. B., Conger, R. D., \& Chyi-In, W. (1991). Intergenerational transmission of harsh parenting. Developmental Psychology, $27,159-171$. http://dx.doi.org/10.1037/0012-1649.27.1.159

Smith, C. A., Ireland, T. O., \& Thornberry, T. P. (2005). Adolescent maltreatment and its impact on young adult antisocial behavior. Child Abuse E Neglect, 29(10), 1099-1119. http://dx.doi.org/10.1016/j.chiabu.2005.02.011

Stith, S., Liu, T., Davies, L., Boykin, E., Alder, M., Harris, J., Som, A., McPherson, M., \& Dees, J. (2009). Risk factors in child maltreatment: A meta-analytic review of the literature. Aggressive and Violent Behavior, 14, 13-29.

Stoltenborgh, M., Bakermans-Kranenburg, M. J., van Ijzendoorn, M. H., \& Alink, L. R. (2013). Cultural-geographical differences in the occurrence of child physical abuse? A meta-analysis of global prevalence. International Journal of Psychology, 48(2), 81-94. http://dx.doi.org/10.1080/00207594.2012.697165

Straus, M. A., Gelles, R. J., \& Steinmetz, S. K. (1980). Behind closed doors: Violence in the American family. New York: Anchor Books.

Straus, M. A., \& Kantor, G. K. (1994). Corporal punishment of adolescents by parents: A risk factor in the epidemiology of depression, suicide, alcohol abuse, child abuse, and wife beating. Adolescence, 29(115), 543-561.

Thornberry, T. P., \& Henry, K. L. (2013). Intergenerational continuity in maltreatment. Journal of Abnormal Child Psychology, 41(4), 555-569. http://dx.doi.org/10.1007/s10802-012-9697-5

Ünal, G. (2005). Domestic violence. Journal of Family E' Society, 8(2), 85-92.

U.S. Department of Health and Human Services. (2006). Administration on Children, Youth and Families. In Child Maltreatment. Washington, DC: U.S. Government Printing Office.

Uslu, R. I., Kapci, E. G., Yildirim, R., \& Oney, E. (2010). Sociodemographic characteristics of Turkish parents in relation to their recognition of emotional maltreatment. Child Abuse E Neglect, 34(5), 345-353. http://dx.doi.org/10.1016/j.chiabu.2009.09.013

Whipple, E. E., \& Webster-Stratton, C. (1991). The role of parental stress in physically abusive families. Child Abuse E Neglect, 15(3), 279-291.

Wolfe, D., Edwards, B., Manion, I., \& Koverola, C. (1988). Early intervention for parents at risk of child abuse and neglect: A preliminary investigation. Journal of Consulting and Clinical Psychology, 56, 40-47.

Zaidi, L. Y., Knutson, J. F., \& Mehm, J. G. (1989). Transgenerational patterns of abusive parenting: Analog and clinical tests. Aggressive Behavior, 15, 137-152. 